\title{
Ensino de Química para surdos: uma revisão bibliográfica
}

\section{Chemistry Teaching for deaf: a bibliographic review}

\section{Caroline Teixeira Guedes ${ }^{1}$, Eluzir Pedrazzi Chacon ${ }^{2}$}

1 Licenciada e Bacharel em Química, Universidade Federal Fluminense, Niterói, RJ, Brasil - carolineg@id.uff.br/ORCID: 0000-0001-5795-6909

2 Doutora em Química Orgânica, Universidade Federal Fluminense/Programa de Pós-graduação em Ensino de Ciências da Natureza, Niterói, RJ, Brasil - eluzir_pedrazzi@id.uff.br/ORCID: 0000-0002-1939-6506

\section{Recebido em Abril/2019. Publicado em Abril/2020}

\section{Palavras-chave:}

Surdez, Aluno Surdo,

Química em Libras,

Ensino de Química.

\section{Keywords:}

Deafness, Deaf Students, Chemistry in Libras, Chemistry Teaching.
RESUMO: Alunos surdos, professores e intérpretes de Libras têm enfrentado muitos obstáculos na comunicação dentro de sala de aula, em especial quando se trata de algumas Ciências, como a Química. A carência de sinais específicos e materiais didáticos, entre outros fatores, são os grandes responsáveis pelas dificuldades no processo de ensino-aprendizagem dessa Ciência para o discente surdo. Diante deste cenário, o presente artigo objetiva examinar as dificuldades existentes e as propostas que têm sido desenvolvidas a fim de minimizá-las, através de uma pesquisa bibliográfica em 9 periódicos e anais de 5 eventos nacionais na área de Ensino de Ciências e Química, disponíveis on-line, referentes aos anos de 2010 a 2018, utilizando para a busca os descritores: 'surdez', 'surdo', 'libras', 'inclusão', 'inclusiva' e 'deficiência auditiva'. A análise dos trabalhos e artigos permitiu constatar que as pesquisas na área são recentes e escassas, uma vez que foram encontrados apenas 15 artigos tratando de assuntos educacionais voltados para Ensino de Química e surdez e que dos 14.153 trabalhos encontrados na busca feita nos anais dos eventos científicos, apenas 143 eram voltados para a temática. Além das dificuldades já citadas, foi observada uma necessidade de reorganização dos cursos de formação de professores, bem como o desenvolvimento de pesquisas com objetivo de criar novas metodologias e estratégias de ensino, em especial, aquelas voltadas para a criação de sinais.

ABSTRACT: Deaf students, teachers and interpreters from Libras (Brazilian sign language) have faced many obstacles in communicating with each other within the classroom, especially when it comes to some sciences such as Chemistry. The lack of specific signs and didactic materials, among other factors, are the main responsible for the difficulties in the teaching-learning process of this Science for the deaf student. In view of this scenario, this article aims to examine the existing difficulties and the proposals that have been developed in order to minimize them, through a bibliographical research in 9 periodicals and annals of 5 national events in Education Science and Chemistry area, available online, for the years 2010 to 2018, using the following descriptors: 'deafness', 'deaf', 'pounds', 'inclusion', 'inclusive' and 'hearing impairment'. The analysis of the works and articles showed that the research in the area is recent and scarce, since only 15 articles were found dealing with educational subjects related to Chemistry Teaching and deafness, and that of the 14.153 works found in the search done in the annals, only 143 were focused on the theme. In addition to the difficulties mentioned above, there was a need for reorganization of teacher training courses, as well as the development of research aimed at creating new methodologies and teaching strategies, especially research aimed at the creation of signals.

\section{INTRODUÇÃO}


A Política Nacional de Educação Especial na Perspectiva da Educação Inclusiva caracteriza o aluno deficiente como sendo o indivíduo cuja participação na escola e na sociedade não é considerada plena e efetiva, devido a determinados impedimentos que podem ser físicos, mentais, sensoriais ou intelectuais (BRASIL, 2008). Incluir estes alunos no ambiente escolar requer um preparo por parte não só dos docentes, mas da escola como um todo. O fato da escola, muitas vezes, contar com professores que não são preparados nos cursos de Licenciatura para lidar com a inclusão, gera inúmeros entraves tanto nas relações interpessoais quanto no processo de ensino-aprendizagem em si. O desafio torna-se ainda maior quando se trata de um aluno surdo, devido à dificuldade de comunicação. Ademais, a ausência de materiais didáticos e de recursos específicos para auxiliar o docente, aliada ao desinteresse por parte dos familiares dos alunos, entre outros fatores, configuram as muitas dificuldades enfrentadas neste contexto (MONTEIRO; CAMARGO; FREITAS, 2016).

Sousa e Goés (1999) descrevem o fracasso da educação brasileira ao tentar lidar com alunos cegos, surdos, deficientes mentais, entre outros, uma vez que se faz necessário não somente novas metodologias, mas uma nova visão política e ideológica do que vem a ser a escola. Hoje, cerca de vinte anos depois, essa mudança continua sendo necessária, uma vez que a educação e a inclusão precisam envolver a garantia não só do acesso, mas também da permanência do discente deficiente na escola, de forma, como apontado por Dutra (2006), que ele se sinta parte não só do ambiente escolar, mas da estrutura social em geral.

De acordo com dados da Pesquisa Nacional de Saúde - PNS 2013 (BRASIL, 2015) $1,1 \%$ da população brasileira possui deficiência auditiva, em um total de $6,2 \%$ da população com algum tipo de deficiência (auditiva, visual, física e intelectual). Segundo a pesquisa, o número significativo de pessoas com deficiência auditiva com nenhum ou baixo nível de instrução revela a dificuldade destes indivíduos de serem incluídos no ambiente escolar.

Em se tratando da educação de surdos, Bisol e Valentini $(2011$; 2014) mostram que dependendo da perspectiva analisada - orgânica ou histórica e cultural - existe diferença entre surdez e deficiência auditiva. Na perspectiva orgânica estas duas palavras são sinônimos, mas na perspectiva histórica e cultural, surdos e deficientes auditivos são indivíduos com uma visão diferente de seu estado físico. Os surdos não se consideram deficientes, mas pessoas com uma comunidade própria, com sua cultura, história, arte e língua. Enquanto "os deficientes auditivos seriam as pessoas que não se identificam com a cultura e a comunidade surda" (BISOL; VALENTINI, 2014, p.232). Esta diferença de perspectiva deve estar bem clara na mente do professor quando se deparar com esta realidade em sua sala de aula, pois "compreender as especificidades da surdez, da cultura surda, da língua de sinais e de como se 
dá a aquisição da escrita pela pessoa surda é fundamental para o educador intervir adequadamente no processo de ensino e aprendizagem" (BISOL; VALENTINI, 2014, p.232).

Neste sentido, Santos (2009) descreve que, apesar de lento, tem havido certo avanço, em especial ao se tratar da educação de surdos. Segundo o autor, tem sido possibilitada uma reconstrução no que diz respeito à educação destes sujeitos, gerada pelo avanço nas discussões referentes ao assunto. Ressalta ainda, a importância da escola entender que a comunidade surda possui uma cultura própria e que o aluno surdo possui uma identidade que precisa ser construída e cujo processo de construção pode ser dificultado ou facilitado à medida que os ouvintes reconhecem suas diferenças e as respeitam.

A partir de 2002, a Língua Brasileira de Sinais (Libras) foi reconhecida como a segunda língua oficial do país, com a aprovação da chamada Lei-Libras (Lei $n^{\circ}$ 10.436), regulamentada pelo decreto $\mathrm{n}^{\circ} 5.626$, de 22 de dezembro de 2005, no qual o Artigo $2^{\circ}$ considera "a pessoa surda aquela que, por ter perda auditiva, compreende e interage com o mundo por meio de experiências visuais, manifestando sua cultura principalmente pelo uso da Língua Brasileira de Sinais - LIBRAS” (BRASIL, 2005). Diante disso, tornou-se necessário criar propostas educacionais bilíngues e biculturais, respeitando a língua, a cultura e a identidade do surdo, uma vez que se pretendia não apenas incluir estes indivíduos no contexto escolar, mas também possibilitar que a aprendizagem fosse facilitada (SALDANHA, 2011).

É importante que a opinião do surdo seja sempre considerada bem como o que ele considera melhor para sua própria educação. Deste modo, na educação de surdos, os professores e os intérpretes são duas figuras de grande importância. Vários autores, tais como: Almeida; Vitaliano (2012); Benite et al. (2009) e Quadros (2003), chamam a atenção em seus trabalhos para a importância de melhorar a formação de professores fazendo com que estes indivíduos saiam da universidade compreendendo o conceito de inclusão, o que é imprescindível para o sucesso da educação inclusiva. No entanto, apesar da Libras ter sido incluída como disciplina curricular obrigatória nos cursos de formação de professores e Fonoaudiologia (BRASIL, 2005), nem todos os professores a conhecem com profundidade, uma vez que o que se aprende nesta disciplina permite que se estabeleça uma comunicação básica levando-se, assim, à necessidade da presença de intérpretes nas salas de aula.

O Intérprete da Língua de Sinais (ILS) não é um tradutor de uma língua para a outra, mas é responsável por potencializar a transmissão do conhecimento para o surdo. Conforme ressalta Perlin (2006), os intérpretes realizam uma tradução da cultura, da língua, da história, da subjetividade surda, intermediando dois mundos, inserindo a cultura no significado de cada conceito interpretado. Com isso, os intérpretes inseridos em aulas de Ciências enfrentam um 
grande desafio uma vez que a maior parte destes profissionais desconhece a linguagem científica, tornando difícil interpretar um contexto desconhecido por ele, o que pode levar a simplesmente uma tradução entre as línguas, que também acaba sendo dificultada pela ausência de sinais específicos.

De acordo com Oliveira e Benite (2015), ao se ter em sala um professor que domina apenas a linguagem científica e um intérprete que domina apenas a linguagem de sinais, a falta de associação entre as duas partes pode levar a um comprometimento no processo de ensino-aprendizagem do aluno surdo, mostrando a necessidade de uma boa relação professorintérprete-aluno.

Diante do cenário apresentado buscou-se neste trabalho, que é um recorte da Monografia de Final de Curso de Licenciatura em Química (GUEDES, 2017) acrescido da pesquisa realizada no ano de 2018, fazer uma revisão bibliográfica a fim de encontrar maiores detalhes a respeito do ensino de Química para surdos no Brasil e do que tem sido feito a fim de superar as dificuldades presentes no processo de ensino-aprendizagem para este público.

\section{METODOLOGIA}

O presente artigo configura-se como uma pesquisa bibliográfica realizada mediante coleta e análise de trabalhos apresentados em 5 eventos nacionais de Ensino de Ciências e Química, que abordam também a Inclusão, e de artigos publicados em 9 periódicos nacionais. A pesquisa deu ênfase aos trabalhos voltados para o ensino e aprendizagem de Química para surdos e deficientes auditivos inclusos nos Ensinos Médio e Superior, apresentados e/ou publicados no período de 2010 a 2018.

A primeira parte da pesquisa bibliográfica foi realizada nos anais de cinco eventos nacionais sobre ensino de Química e Ciências. São eles: Encontro Nacional de Ensino de Química (ENEQ), Simpósio Brasileiro de Educação Química (SIMPEQUI), Congresso Brasileiro de Química (CBQ), Reunião Anual da Sociedade Brasileira de Química (RASBQ) e Encontro Nacional de Pesquisa em Educação em Ciências (ENPEC). O período de 2010 a 2018 foi escolhido baseado na pesquisa bibliográfica realizada por Ferreira, Nascimento e Pitanga (2014) nos anais da RASBQ, no período de 2002 a 2012, voltada para a mesma temática abordada neste trabalho, na qual os autores constataram que dos 1.968 resumos encontrados, apenas 11 tratavam da temática pesquisada. Além disso, uma busca pelos trabalhos apresentados no ano anterior ao da pesquisa (2009), teve como resultado um total de 2 trabalhos sobre ensino de Química para surdos no ENPEC, 1 trabalho tanto no SIMPEQUI quanto no $\mathrm{CBQ}$, enquanto que na RASBQ não houve nenhum trabalho. Diante deste fato, 
decidiu-se realizar a pesquisa a partir do ano de 2010, quando passou a surgir um quantitativo considerável de trabalhos voltados para a temática abordada nos eventos analisados.

$\mathrm{Na}$ segunda parte da pesquisa bibliográfica realizada foram analisados artigos publicados em revistas voltadas para o ensino de Ciências e de Química, escolhidas levandose em consideração a facilidade de acesso docente e o Qualis CAPES no quadriênio 20132016. As revistas selecionadas foram: Revista Ciência \& Educação, Revista Brasileira de Estudos Pedagógicos (RBEP), Revista Areté, Revista Brasileira de Pesquisa em Educação em Ciências (RBPEC), Revista Brasileira de Ensino de Ciência e Tecnologia (RBECT), Investigações em Ensino de Ciências (IENCI), Química Nova na Escola Online (QNEsc), Revista Brasileira de Ensino de Química (ReBEQ) e Ensino de Ciências e Tecnologia em Revista (ENCITEC). A Tabela 1 mostra a classificação na área de Ensino de cada periódico no Qualis CAPES.

Após uma revisão da bibliografia a respeito da educação de surdos no Brasil, foi realizada uma busca nos sites das revistas e eventos, utilizando-se os seguintes descritores: 'surdez', ‘surdo', 'libras', ‘inclusão', ‘inclusiva', e 'deficiência auditiva'. Os artigos encontrados foram analisados, assim como os resumos dos trabalhos, a fim de identificar os conteúdos das pesquisas, as dificuldades relacionadas ao ensino de Química para surdos e deficientes auditivos e o que tem sido feito a respeito.

Tabela 1 - Classificação das revistas analisadas no Qualis CAPES.

\begin{tabular}{c|c} 
Revista & $\begin{array}{c}\text { Qualis CAPES na área de } \\
\text { Ensino }\end{array}$ \\
\hline Ciência \& Educação & $\mathrm{A} 1$ \\
\hline RBEP & $\mathrm{A} 1$ \\
\hline Revista Areté & $\mathrm{A} 2$ \\
\hline RBPEC & $\mathrm{A} 2$ \\
\hline RBECT & $\mathrm{A} 2$ \\
\hline IENCI & $\mathrm{A} 2$ \\
\hline QNEsc & $\mathrm{B} 1$ \\
\hline ReBEQ & $\mathrm{B} 1$ \\
\hline ENCITEC & $\mathrm{B} 1$ \\
\hline
\end{tabular}

Fonte:https://sucupira.capes.gov.br/sucupira/public/consultas/coleta/veiculoPublicacaoQualis/li staConsultaGeralPeriodicos.jsf. Acesso em: 23/01/2019.

Para os trabalhos apresentados em eventos, que se expuseram em maior número, foi realizada também uma análise considerando as regiões do Brasil em que as pesquisas estão sendo realizadas. 
Os trabalhos e os artigos foram divididos em 6 categorias de acordo com o conteúdo dos resumos, sendo elas: (1) narrativas dos sujeitos; (2) desenvolvimento de metodologias e instrumentos; (3) pesquisa, análise e/ou criação de sinais; (4) revisão bibliográfica (5) formação de docentes e (6) papel dos intérpretes.

Por fim, foi analisado o conteúdo de todos os artigos e dos trabalhos inclusos nas duas categorias nas quais se enquadraram a maior parte das pesquisas.

\section{RESULTADOS E DISCUSSÃO}

Para uma melhor compreensão, os resultados serão apresentados separadamente em dois momentos: (I) Trabalhos apresentados em eventos nacionais e (II) Artigos publicados em revistas nacionais.

\subsection{Análise de trabalhos apresentados em eventos nacionais}

A Tabela 2 apresenta os dados numéricos obtidos ao relacionar o número total de trabalhos publicados nos eventos selecionados no período compreendido entre 2010 e 2018 e o número de trabalhos envolvendo a temática, os quais foram encontrados através do sistema de busca dos sites contendo os anais de cada evento, utilizando os descritores. Vale ressaltar que o ENEQ e o ENPEC são eventos bienais e que na RASBQ e no CBQ foram quantificados apenas os trabalhos inclusos na área de ensino. É importante considerar também que o ENPEC engloba trabalhos voltados para outras Ciências, além da Química, o que explica o maior número total de trabalhos. A quantificação apresentada na Tabela 2 considera apenas os trabalhos disponíveis nos sites, sendo os valores apresentados divergentes de alguns valores presentes nos relatórios técnicos.

Tabela 2 - Número de trabalhos publicados em anais de Eventos nacionais envolvendo o Ensino de Química para surdos no período de 2010 a 2018.

\begin{tabular}{c|c|c|c}
\hline Congresso & $\begin{array}{c}\text { Trabalhos voltados } \\
\text { para o Ensino de } \\
\text { Química }\end{array}$ & $\begin{array}{c}\text { Trabalhos } \\
\text { envolvendo a } \\
\text { temática }\end{array}$ & $\begin{array}{c}\text { Percentual dos } \\
\text { trabalhos envolvendo a } \\
\text { temática em relação a } \\
\text { quantidade total }\end{array}$ \\
\hline ENEQ & 4175 & 70 & $1,68 \%$ \\
\hline SIMPEQUI & 1537 & 19 & $1,24 \%$ \\
\hline CBQ & 2302 & 24 & $1,04 \%$ \\
\hline RASBQ & 1402 & 14 & $1,00 \%$ \\
\hline ENPEC & 4737 & 16 & $0,34 \%$ \\
\hline
\end{tabular}

Fonte: Dados trabalhados pela primeira autora. 
A partir dos dados da Tabela 2, foram construídos gráficos apresentando o número de trabalhos envolvendo a temática pesquisada em cada evento dentro do período analisado (Figura 1) e o percentual de trabalhos envolvendo a surdez em relação ao número total de trabalhos (Figura 2).

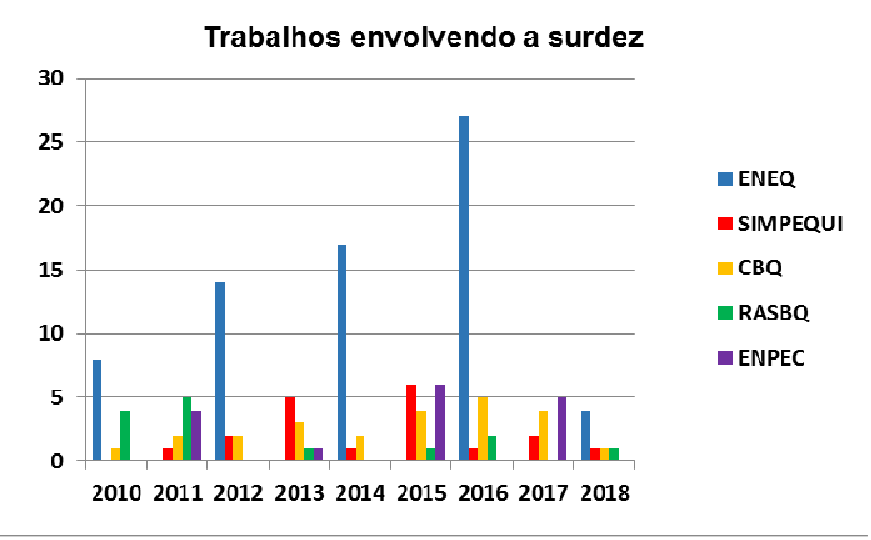

Figura 1 - Número de trabalhos envolvendo a surdez e o Ensino de Química apresentados em eventos nacionais, no período de 2010 a 2018.

Fonte: Dados trabalhados pela primeira autora.

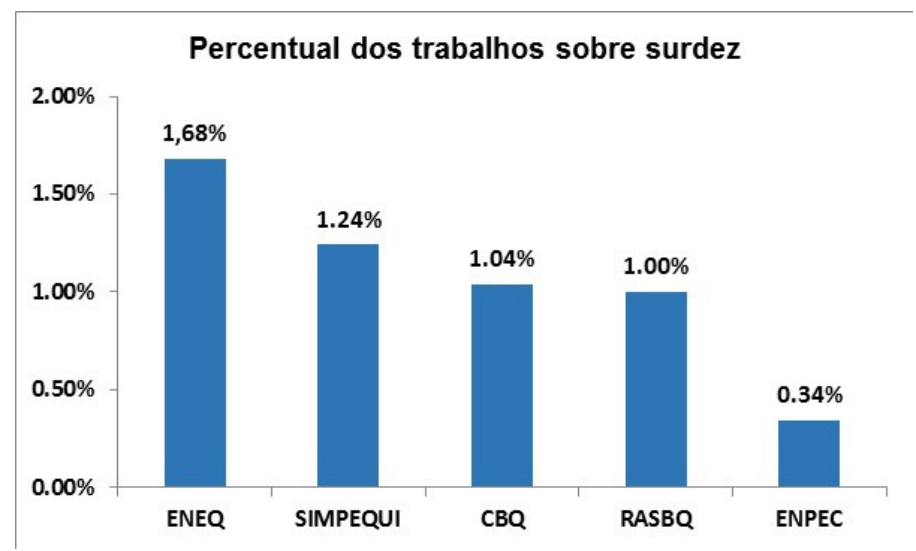

Figura 2 - Percentual referente aos trabalhos envolvendo a temática calculado em relação ao número total de trabalhos em cada evento.

Fonte: Dados trabalhados pela primeira autora.

A análise das quantificações gerais (Tabela 2) e o gráfico da Figura 2 permitem observar a grande discrepância em relação ao número total de trabalhos e o número de trabalhos envolvendo a temática pesquisada. Ainda que se desconsiderem os trabalhos do ENPEC, uma vez que ele envolve outras Ciências, tem-se mais de 9.000 trabalhos, dos quais apenas 143 são voltados para o ensino de Química e a surdez, o que corresponde a menos de $2 \%$ do número total de trabalhos, demonstrando uma carência de pesquisas na área.

Os gráficos das Figuras 1 e 2 mostram ainda que o ENEQ se destaca nas pesquisas voltadas para a temática abordada, contudo isso se deve ao seu maior número total de trabalhos, que por sua vez pode estar relacionado a uma preferência dos participantes em 
apresentar seus trabalhos neste evento em relação aos demais, visto que se trata de um evento maior. De 2010 a 2017 o ENEQ foi o único evento em que o número de trabalhos não sofreu nenhuma queda ao longo dos anos, o que comprova a preferência dos autores em relação a ele. A queda na quantidade total de trabalhos em 2018 pode ser devida ao local onde o evento foi realizado (estado do Acre), mas apesar disso o percentual de trabalhos voltados para a temática em relação ao número total de trabalhos se manteve. Entretanto, o gráfico da Figura 2 mostra que, apesar do maior número de trabalhos no ENEQ, o percentual de trabalhos envolvendo a surdez é bem próximo ao dos eventos menores, o que comprova a carência de trabalhos na área ou a pouca divulgação destes trabalhos em eventos científicos.

Buscou-se também verificar em quais regiões do Brasil as pesquisas sobre a surdez e o Ensino de Química têm sido desenvolvidas. No gráfico mostrado na Figura 3 é possível observar que a região Centro-Oeste é onde se concentra a maior quantidade de trabalhos (40), graças a um grande número de pesquisas que têm sido desenvolvidas no estado de Goiás (32).

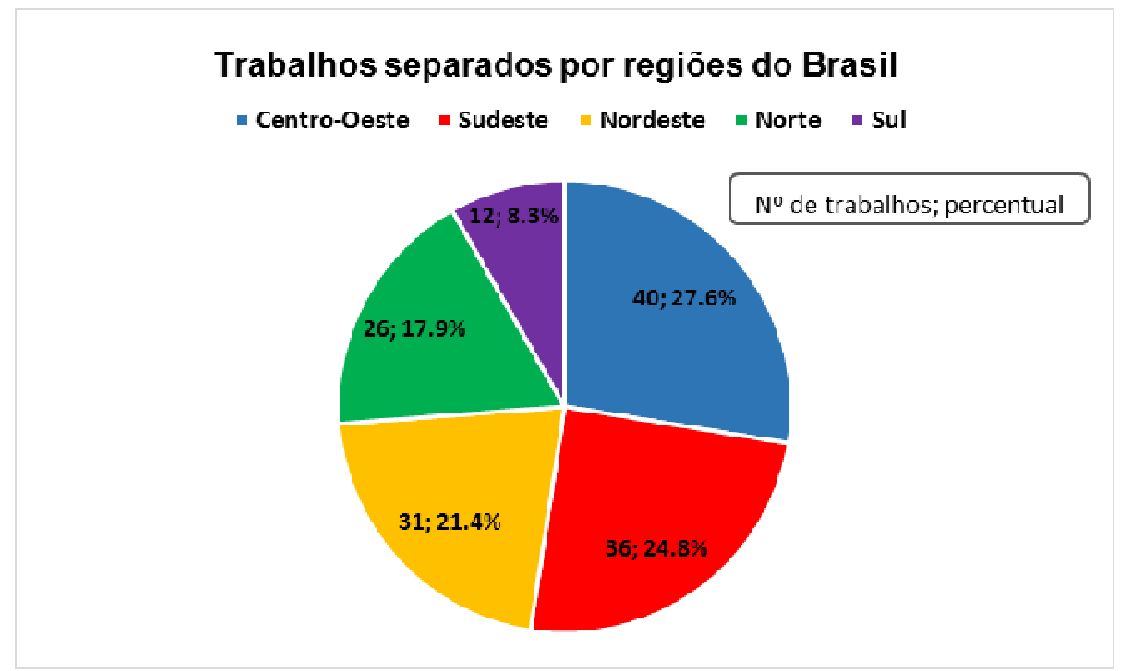

Figura 3 - Número total e percentual de trabalhos de todos os congressos analisados envolvendo a surdez e o ensino de Química, separados por regiões do Brasil.

Fonte: Dados trabalhados pela primeira autora.

Nota-se que Goiás e Rio de Janeiro, são os dois únicos estados que possuem representantes em todos os eventos analisados, apesar do Rio de Janeiro possuir um pequeno número de trabalhos totais nesta área. Vale considerar que o gráfico apresenta um total de 145 trabalhos, uma vez que dois trabalhos contavam com a participação de autores de dois estados diferentes. Uma possível explicação para o destaque do estado de Goiás é dada por Pereira, Benite e Benite (2011, p. 50), ao esclarecer que "todas as escolas do estado de Goiás são inclusivas por efeito de lei". A esse respeito, Lorena Resende, gerente de Ensino Especial da Secretaria de Estado de Educação, Cultura e Esporte (SEDUCE) de Goiás, afirma ainda que "1.050 escolas estão espalhadas por todo estado trabalhando com a educação inclusiva" (PORTAL BRASIL, 2016). Observa-se que dos 32 trabalhos desenvolvidos no estado de 
Goiás, 19 são de autoria ou orientação de professores do Laboratório de Pesquisas em Educação Química e Inclusão - LPEQI da Universidade Federal de Goiás (UFG) e da Rede Goiana Interdisciplinar de Pesquisas em Educação Inclusiva - RPEI.

Entre as demais regiões, a Sudeste apresentou um percentual bem próximo da Centro-Oeste, com destaque para os estados de Minas Gerais (15 trabalhos) e São Paulo (10 trabalhos). Enquanto que a região Sul apresentou um menor percentual, com apenas 12 trabalhos ao longo dos 9 anos analisados, fato inesperado uma vez que se trata da região com maior número de pessoas com deficiência auditiva de acordo com dados da Pesquisa Nacional de Saúde (BRASIL, 2015).

Contudo, é importante ressaltar que a quantificação apresentada nesta pesquisa envolve trabalhos voltados apenas para o ensino de Química, indicando que os estados e regiões que apresentaram um maior quantitativo não são os únicos onde há pesquisadores preocupados com o ensino de surdos em geral, mas aqueles em que, nesse caso específico, tem gerado um número mais pronunciado de pesquisas nesta área.

Por último, foi realizada uma categorização dos trabalhos, separando-os entre as seguintes categorias: (1) narrativas dos sujeitos; (2) desenvolvimento de metodologias e instrumentos; (3) pesquisa, análise e/ou criação de sinais; (4) revisão bibliográfica (5) formação de docentes e (6) papel dos intérpretes. Essa categorização foi feita baseada no título e conteúdo dos resumos dos trabalhos. Cabe observar que um maior número de trabalhos totais se deve ao fato de que alguns se encaixaram em mais de uma categoria. $\mathrm{O}$ gráfico da Figura 4 permite identificar quais categorias se destacam em cada evento.

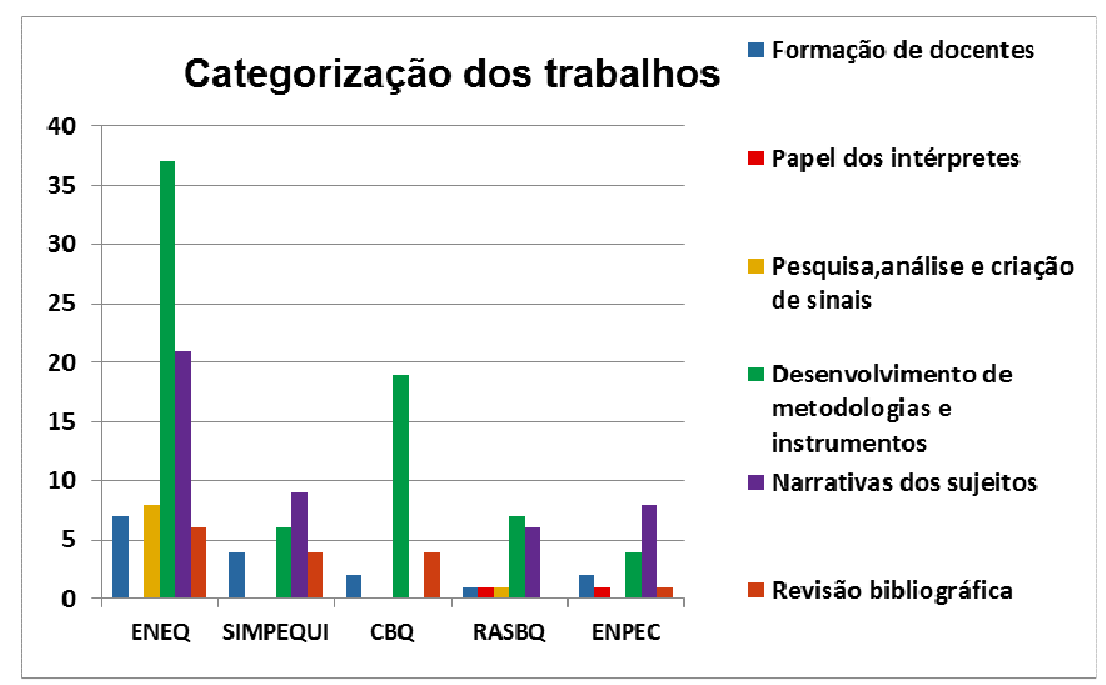

Figura 4 - Número de trabalhos em cada evento separado por categorias.

Fonte: Dados trabalhados pela primeira autora.

A análise do gráfico da Figura 4 mostra que a maior parte dos trabalhos está voltada para o "Desenvolvimento de metodologias e instrumentos" (73) e para as "Narrativas dos 
sujeitos" (44). Na primeira, há um grande destaque para o desenvolvimento de recursos visuais que facilitem o aprendizado da Química pelo aluno surdo, mostrando onde se encontra a maior preocupação dos pesquisadores. Já a segunda comprova uma preocupação por parte dos pesquisadores em entender a visão dos sujeitos envolvidos neste processo de ensinoaprendizagem, a fim de identificar fatores como: as maiores dificuldades, os métodos de ensino e avaliação, e as relações estabelecidas entre eles, principalmente.

No ENEQ observou-se um maior número de trabalhos nas categorias 1 e 2, isto é, "Desenvolvimento de metodologias e instrumentos" (37) e "Narrativas dos sujeitos" (21), na qual os sujeitos são alunos surdos e ouvintes, professores e intérpretes, que foram submetidos a entrevistas e responderam a questionários. No SIMPEQUI o destaque foi também para os trabalhos envolvendo as "Narrativas dos sujeitos" (9). Já no CBQ foi possível analisar que dos 24 trabalhos categorizados, 19 envolviam "Desenvolvimento de metodologias e instrumentos", bem como 7 dos 14 trabalhos apresentados na RASBQ. Observa-se na RASBQ que 6 trabalhos foram voltados para "Narrativas dos sujeitos", categoria que também se destacou no ENPEC ( 8 trabalhos).

Considerando que dentro de cada categoria, as pesquisas ainda apresentam alguns enfoques diferentes, um panorama geral será apresentado a seguir, para essas duas categorias que se destacaram.

Os trabalhos voltados para narrativas dos sujeitos envolvidos no processo de inclusão abrangem estudos de caso, análises através dos diários de aula, relatos de experiência pessoal, entrevistas e questionários com alunos surdos e ouvintes, professores, intérpretes e em alguns casos, coordenadores das escolas, com diversos focos de análise, como: a relação intérpretealuno; as dificuldades no processo de ensino-aprendizagem do aluno surdo e a perspectiva dos ouvintes, bem como os fatores que podem interferir neste processo; o acesso e integração do discente surdo no ensino regular; a formação de professores, assim como a presença da Libras como disciplina nos cursos de Licenciatura; as metodologias de ensino utilizadas em sala de aula; os métodos de avaliação; entre outros.

Já as metodologias e estratégias desenvolvidas consistiam, em geral, na utilização de recursos visuais, como: apostilas ilustradas, imagens, vídeos e slides, histórias em quadrinhos, fotonovela, objetos em 3D, entre outros. Além disso, a experimentação também foi um recurso bastante utilizado em algumas pesquisas, bem como a construção de jogos, dentre os quais se destacam: jogo da memória, quebra-cabeça, cartas, dominó, bingo e Tantram. Entre as temáticas observadas nas experimentações e nos materiais didáticos encontram-se: automedicação, corrosão, cosméticos, nutrição alimentar, petróleo, e também os seguintes 
conteúdos: ácidos e bases, balanceamento de reações químicas, camada de valência, cinética química, estados físicos da água, estrutura atômica, funções orgânicas, isomeria, hidrocarbonetos, lei da conservação das massas, ligações químicas, misturas, reações químicas, soluções, substâncias químicas, tabela periódica, transformações químicas, termoquímica, entre outros.

\subsection{Análise de artigos publicados em revistas nacionais}

Os descritores utilizados para a busca nas revistas nacionais foram os mesmos utilizados na análise anterior e a pesquisa foi realizada, de forma geral, sem considerar um período de tempo específico, diante da pequena quantidade de trabalhos encontrados. Dessa forma, os descritores permitiram encontrar apenas 15 trabalhos envolvendo a temática abordada no presente artigo.

Os trabalhos foram categorizados, conforme mostra a Tabela 3 e os conteúdos analisados.

Tabela 3 - Artigos separados por categorias

\begin{tabular}{c|c}
\hline Categoria & Número de trabalhos \\
\hline Narrativas dos sujeitos & 2 \\
\hline Desenvolvimento de metodologias e instrumentos & 5 \\
\hline Pesquisa, análise e criação de sinais & 2 \\
\hline Revisão bibliográfica & 1 \\
\hline Formação de docentes & 5 \\
\hline Papel dos Intérpretes & 0 \\
\hline
\end{tabular}

Fonte: Dados trabalhados pela primeira autora.

Dois artigos foram categorizados como "Narrativas dos sujeitos". Borges e Costa (2010) publicaram na revista Ciência \& Educação o artigo intitulado "Um estudo de possíveis correlações entre representações docentes e o ensino de ciências e matemática para surdos", no qual cinco professores envolvidos com o ensino de surdos falam a respeito de questões como formação inicial, Língua de Sinais, intérpretes, etc. No artigo, "Aula de Química e Surdez: sobre Interações Pedagógicas Mediadas pela Visão", de Pereira, Benite e Benite (2011) publicado na revista Química Nova na Escola Online (QNEsc), os autores realizam uma pesquisa participante através de questionários e entrevistas com alunos surdos, professores e intérpretes com a finalidade de estabelecer o diálogo com a cultura surda. É possível observar uma grande semelhança tanto entre os dois artigos, quanto entre os artigos e os trabalhos apresentados nos eventos e inseridos nesta mesma categoria. Isso permite comprovar a realidade deste cenário, uma vez que as dificuldades citadas pelos sujeitos se assemelham, bem como suas sugestões de melhoria. 
Na categoria "Desenvolvimento de metodologias e instrumentos" foram encontrados cinco artigos. No artigo "Utilização do jogo de tabuleiro - ludo - no processo de avaliação da aprendizagem de alunos surdos", Ferreira e Nascimento (2014) desenvolveram um jogo de tabuleiro para ser utilizado como método de avaliação da aprendizagem substituindo os métodos tradicionais de avaliação. O método foi aprovado pelos alunos surdos que apresentaram um bom rendimento e se declararam satisfeitos. Fernandes e Reis (2017) trabalharam em uma "Estratégia Didática Inclusiva a Alunos Surdos para o Ensino dos Conceitos de Balanceamento de Equações Químicas e de Estequiometria para o Ensino Médio", por meio do uso de sequências didáticas contendo imagens, experimentos, desenhos e modelos com massinha e bolinha de isopor. Já Zayed, Medeiros e Recena (2016) confeccionaram uma "Cartilha sobre conceitos básicos de Química para inclusão de alunos surdos em sala de aula", que consiste em um livreto contendo conceitos básicos de Química. O objetivo dos autores foi reduzir a dependência dos alunos surdos em relação ao intérprete além de melhorar a interação entre eles e os demais alunos ouvintes. $O$ resultado também foi positivo e o uso da cartilha em outros contextos foi considerado apropriado. O artigo de Zayed, Medeiros e Recena foi publicado na Revista Areté e os demais na revista QNEsc.

Jacaúna e Rizzati (2018) publicaram na revista Areté o artigo "A inclusão de uma aluna surda em aulas de Química Orgânica: Uma proposta para o ensino de Química inclusivo", também inserido na categoria "Desenvolvimento de metodologias e instrumentos". A metodologia consistiu no uso de moléculas feitas de isopor, a fim de facilitar a compreensão da aluna surda em relação aos conceitos de ligações químicas, geometria molecular e ângulos de ligação; materiais voltados para a produção de perfume, com o objetivo de realizar um experimento que envolvesse os conceitos teóricos anteriormente explicados; além de um aplicativo de celular chamado Hand Talk, a fim de promover a comunicação com a aluna e o professor cego que desenvolveu o kit utilizado. A aluna conseguiu realizar o experimento sem grandes dificuldades e assimilar o conteúdo abordado da mesma forma que os demais alunos ouvintes.

Ainda na mesma categoria, encontra-se o artigo "O Ensino de Química para alunos surdos: o conceito de misturas no ensino de Ciências" sob autoria de Mendonça Oliveira e Benite (2017), publicado na Revista QNEsc. Nele os autores descreveram uma intervenção pedagógica realizada numa escola bilíngue, na qual é trabalhado o conceito de "misturas" por meio de atividade prática utilizando materiais do dia a dia. A aula foi ministrada por dois professores, sendo um deles bilíngue (Português/Libras), logo não houve a participação de intérprete, o que foi considerado de grande relevância, uma vez que não foi preciso a intermediação entre professor e aluno surdo. 
Na categoria "Pesquisa, análise e criação de sinais" está o artigo "Terminologias Químicas em Libras: A Utilização de Sinais na Aprendizagem de Alunos Surdos", de Sousa e Silveira (2011), publicado na revista (QNEsc). Os autores descrevem as dificuldades encontradas por professores e intérpretes em aulas de Química, devido a ausências de sinais voltados para esta área. A metodologia utilizada envolveu a observação de aulas de Química, aliada a entrevistas com os sujeitos envolvidos no processo de ensino-aprendizagem, a fim de avaliá-los. Os autores realizaram ainda uma pesquisa dos sinais referentes a termos químicos existentes no Dicionário Enciclopédico Ilustrado Trilíngue de Capovilla e Raphael, apresentando alguns através de imagens. Na mesma linha de pesquisa encontra-se o artigo " $A$ importância da Libras: Um olhar sobre o ensino de Química a Surdos”, da revista IENCI, no qual Nogueira, Barroso e Sampaio (2018) realizam um mapeamento dos sinais existentes através de uma pesquisa bibliográfica semelhante à do artigo de Sousa e Silveira (2011), fazendo também uma análise da importância da língua de sinais para o surdo e da realidade educacional desse sujeito, bem como de sua cultura. Foi possível constatar a necessidade de novos sinais referentes a termos químicos, a fim de que os surdos possam adquirir o conhecimento científico e observar que professores e intérpretes não estão sendo preparados para suprir essa necessidade.

O artigo "Dez Anos da Lei da Libras: Um Conspecto dos Estudos Publicados nos Últimos 10 Anos nos Anais das Reuniões da Sociedade Brasileira de Química”, publicado na revista QNEsc, sob autoria de Ferreira, Nascimento e Pitanga (2014), consiste em uma "Revisão bibliográfica" cujo objetivo é identificar questões relacionadas a Libras e ao Ensino de Química apresentadas na Divisão de Ensino da RASBQ, no período de 2002 a 2012. Ressalta-se que a partir das conclusões obtidas neste trabalho, determinou-se o período de análise da presente pesquisa, conforme citado anteriormente. O artigo comprova que as pesquisas voltadas para esta área são recentes e ainda bastante escassas.

Por último, dos cinco artigos inseridos na categoria "Formação de docentes", quatro são de autoria e/ou orientação de Anna M. C. Benite e nem todos tratam exclusivamente da Química e da surdez concomitantemente, mas foram considerados aqui por envolverem a importância da inclusão na formação de professores de Ciências. Os artigos Formação de Professores de Ciências em Rede Social: Uma Perspectiva Dialógica na Educação Inclusiva", publicado na RBPEC, sob a autoria de Benite et al. (2009), "Redes sociais como espaço de interações discursivas sobre formação de professores de ciências para a educação inclusiva", de Pereira e Benite (2012), publicado na IENCI e "Trajetória da formação de professores de ciências para educação inclusiva em Goiás, Brasil, sob a ótica de participantes de uma rede colaborativa”, de Pereira et al. (2015), publicado na Ciência \& 
Educação, possuem semelhança não só na autoria, mas também no teor da pesquisa. Os autores sugerem a criação de uma rede social de pesquisa, por meio de uma pesquisa participante, a fim de gerar um compartilhamento de conhecimento. A rede é formada por um conjunto de pessoas com conexões entre si e é apresentada como uma alternativa para a formação inicial e continuada de professores de Ciências visando à inclusão. Já no artigo " $A$ Educação Inclusiva na percepção dos professores de Química” de Vilela-Ribeiro e Benite (2010), publicado na revista Ciência \& Educação é realizado um questionário com professores de Química a fim de avaliar a visão de cada um sobre a inclusão. Para isso, as respostas foram analisadas mediante o que se espera de uma visão apropriada de inclusão e foi possível concluir que os licenciados têm saído das universidades sendo considerados aptos para exercer o magistério, contudo não estão preparados para lidar com a inclusão. O quinto artigo desta categoria é intitulado "Ressignificando a formação de professores de Química para a Educação Especial e Inclusiva: uma história de parcerias”, de autoria Retondo e Silva (2008), publicado na revista QNEsc. Trata-se de um artigo de grande relevância pois, diferente de muitos artigos que apontam a defasagem na formação dos professores de Ciências em relação a inclusão, ele não apenas expõe o problema, mas também propõe uma solução para o mesmo. O artigo trata de um projeto desenvolvido em um curso de Licenciatura em Química na Universidade de São Paulo, ao longo de uma disciplina com estágio curricular supervisionado. O projeto, voltado para Educação Especial e Inclusiva, envolveu debates e palestra com profissionais da área, além do desenvolvimento de materiais didático-pedagógicos pelos alunos estagiários. Os autores observaram que o projeto gerou uma consciência a respeito da inclusão nos futuros professores de Química, o que tem se mostrado escasso e de grande importância. Os discentes universitários tiveram contato tanto com alunos deficientes quanto com profissionais envolvidos em sua educação, podendo observar as dificuldades envolvidas no processo de ensino-aprendizagem e a importância do desenvolvimento de metodologias e estratégias que possam tornar esse processo viável e eficaz.

A análise dos artigos comprovou, mais uma vez, a escassez de pesquisas na área e que os trabalhos publicados estão mais voltados para uma análise do cenário do ensino de Química e a surdez. Foi possível observar ainda que muitos dos trabalhos apresentados nos congressos científicos não foram publicados como artigos em revistas. 


\section{CONSIDERAÇÕES FINAIS}

A pesquisa bibliográfica permitiu conhecer o que tem sido feito a respeito da educação de surdos, em especial, em relação ao ensino de Química. Foi possível observar que a maior parte dos trabalhos só começou a ser desenvolvida a partir do período compreendido na presente pesquisa, mostrando que são recentes. Em relação aos eventos foram encontrados um total de 143 trabalhos voltados para a temática entre os mais de 9.000 trabalhos apresentados e nos 9 periódicos envolvidos na pesquisa apenas 15 artigos foram identificados, o que comprova que as pesquisas são ainda escassas, mesmo com a possibilidade de haverem outros trabalhos e artigos não identificados pelos descritores utilizados.

A análise do conteúdo dos artigos e dos resumos dos trabalhos permitiu concluir que as dificuldades no processo de ensino de Química para surdos se devem a diversos fatores, entre os quais se encontra a defasagem na formação de professores, que saem da universidade considerados aptos para o magistério, contudo não são preparados para lidar com a perspectiva inclusiva, o que os leva a dependerem de um intérprete quando possuem um aluno surdo. Entretanto, o intérprete, em geral, não possui conhecimento científico, o que, aliado a ausência de sinais referentes a termos químicos, dificulta ainda mais a comunicação gerando conflitos na relação professor-aluno-intérprete.

Apesar do cenário não muito animador, a categorização dos trabalhos permitiu observar que a maior parte deles envolve o desenvolvimento de metodologias, o que se mostrou bastante positivo, visto que embora muitos trabalhos apenas descrevam o cenário do ensino de Química para surdos, através de questionários e entrevistas com alunos, professores e intérpretes, há uma quantidade considerável de estratégias que têm sido testadas e aprovadas e que podem ser utilizadas por professores que possuem discentes surdos em suas salas de aula, facilitando a compreensão da Química para os mesmos. Entre as estratégias encontramse o uso de recursos visuais como imagens, vídeos, objetos 3D, além dos jogos e experimentos.

A carência de trabalhos envolvendo ensino de Química e surdez comprova que há um trabalho árduo a nossa frente para que os indivíduos surdos aprendam essa Ciência, bem como aponta para a necessidade de uma mudança de postura profissional para encararmos as dificuldades apresentadas. Ressalta-se a necessidade de elaboração de novas estratégias e recursos, mas também do desenvolvimento de uma perspectiva inclusiva de todos os indivíduos considerados "normais" em relação aqueles que são "diferentes". A inclusão precisa começar nas relações interpessoais, sendo indispensável na formação dos docentes. Atitudes simples como uma boa iluminação na sala de aula e/ou um posicionamento correto 
do professor a fim de facilitar a leitura labial podem potencializar o processo de ensinoaprendizagem sem que sejam necessários grandes esforços. É preciso que haja, acima de tudo, uma compreensão a respeito da história, cultura e diferenças dos indivíduos surdos e uma preocupação voltada para inclusão não só desses indivíduos, mas de todos os outros que acabam de uma forma ou de outra sendo excluídos das escolas.

\section{REFERÊNCIAS BIBLIOGRÁFICAS}

ALMEIDA, J. J. F.; VITALIANO, C. R. A disciplina de libras na formação inicial de pedagogos: experiência dos graduandos. Seminário de pesquisa em educação da região Sul, 2012. Disponível em: <http:// www.ucs.br/etc/conferencias/index.php/anpedsul/ 9anpedsul/paper/viewFile/2429/582>. Acesso em: 02 fev. 2019.

BENITE, A. M. C. PEREIRA, L. L. S.; BENITE, C. R. M; PROCÓPIO, M. V. R.; FRIEDRICH, M. Formação de professores de ciências em rede social: uma perspectiva dialógica na educação inclusiva. Revista Brasileira de Pesquisa em Ensino de Ciências, v. 9, n. 3, 2009.

BISOL, C. A.; VALENTINI, C. B. Surdez e Deficiência Auditiva - qual a diferença? Objeto de Aprendizagem Incluir - UCS/FAPERGS, 2011. Disponível em:

$<$ http://www.grupoelri.com.br/Incluir/downloads/OA_SURDEZ_Surdez_X_Def_Audit_Text o.pdf>. Acesso em: 02 fev. 2019.

BISOL, C. A.; VALENTINI, C. B. Objeto Virtual de Aprendizagem Incluir: Recurso para a formação de professores visando a inclusão. Revista Brasileira de Educação Especial, Marília, v. 20, n. 2, p. 223-234, Abr.-Jun., 2014.

BORGES, F. A.; COSTA, L. G. Um estudo de possíveis correlações entre representações docentes e o Ensino de Ciências e Matemática para surdos. Ciência \& Educação, Bauru, v. 16, n. 3, p. 567-583, 2010.

BRASIL. Decreto Federal n 5.626 de 22 de dezembro de 2005. Regulamenta a Lei no 10.436, de 24 de abril de 2002, que dispõe sobre a Língua Brasileira de Sinais - Libras, e o art. 18 da Lei no 10.098, de 19 de dezembro de 2000. Diário Oficial da União, Brasília - DF, 2005.

BRASIL. Política Nacional de Educação Especial na Perspectiva da Educação Inclusiva. Brasília: Ministério da Educação, Secretaria de Educação Especial, 2008. Disponível em: $<$ http://portal.mec.gov.br/arquivos/pdf/politicaeducespecial.pdf> $>$. Acesso em: 01 fev. 2019.

BRASIL. IBGE - Instituto Brasileiro de Pesquisa e Estatística. Pesquisa Nacional de Saúde 2013: Ciclos da Vida: Brasil e Grandes Regiões. Coordenação de Trabalho e Rendimento. Rio de Janeiro, 2015.

DUTRA, C. P. Editorial. Revista da Educação Especial/Ministério da Educação, Secretaria de Educação Especial. v. 1, n. 1, Brasília: Secretaria de Educação Especial, 2006.

FERNANDES, J. M.; REIS, I. F. Estratégia didática inclusiva a alunos surdos para o ensino dos conceitos de balanceamento de equações químicas e de estequiometria para o Ensino Médio. Química Nova na Escola, São Paulo, v. 39, n. 2, p. 186-194, 2017.

FERREIRA, W. M.; NASCIMENTO, S. P. F. Utilização do jogo de tabuleiro - ludo - no processo de avaliação da aprendizagem de alunos surdos. Química Nova na Escola, São Paulo, v. 36, n. 1, p. 28-36, 2014.

FERREIRA, W. M.; NASCIMENTO, S. P. F.; PITANGA, A. F. Dez Anos da Lei da Libras: Um Conspecto dos Estudos Publicados nos Últimos 10 Anos nos Anais das Reuniões da 
Sociedade Brasileira de Química. Química Nova na Escola, São Paulo, v. 36, n. 3, p. 185193, 2014.

GUEDES, C. T. Ensino de Química em Libras: uma análise crítica. Monografia de Final de Curso de Licenciatura em Química - Universidade Federal Fluminense, Niterói, 2017, 91p.

JACAÚNA, R. D. P.; RIZZATTI, I. M. A inclusão de uma aluna surda em aulas de Química Orgânica: Uma proposta para o ensino de Química inclusivo. Areté - Revista Amazônica de Ensino de Ciências, Manaus, v.11, n. 23, 2018.

MENDONÇA, N. C. S.; OLIVEIRA, A. P.; BENITE, A. M. C. O Ensino de Química para alunos surdos: o conceito de misturas no ensino de Ciências. Química Nova na Escola, São Paulo, v. 39, n. 4, p. 347-355, 2017.

MONTEIRO, M. B.; CAMARGO, E. A. A.; FREITAS, A. P. Reflexões sobre práticas de ensino e inclusão. Journal of Research in Special Educational Needs, v.16, n.s1, p. 940944, 2016.

NOGUEIRA, E. P.; BARROSO, M. C. S.; SAMPAIO, C. G. A importância da Libras: Um olhar sobre o ensino de Química a Surdos. Investigações em Ensino de Ciências, Porto Alegre, v. 23, n. 2, p. 49-64, 2018.

OLIVEIRA, W. D.; BENITE, A. M. C. Estudos sobre a relação entre o intérprete de LIBRAS e o professor: implicações para o ensino de ciências. Revista Brasileira de Pesquisa em Educação em Ciências, v. 15, n. 3, 2015.

PERLIN, L.L.S. A cultura surda e os intérpretes de Língua de Sinais (ILS). ETD - Educação Temática Digital, Campinas, v.7, n.2, p.136-147, 2006.

PEREIRA, L. L. S.; BENITE, C. R. M.; PADILHA, J. C.; MENDES, M. L.; BENITE, A. M. C.; VILELA-RIBEIRO, E. B. Trajetória da formação de professores de ciências para educação inclusiva em Goiás, Brasil, sob a ótica de participantes de uma rede colaborativa. Ciência \& Educação, Bauru, v. 21, n. 2, p. 473-491, 2015.

PEREIRA, L. L. S.; BENITE, C. R. M.; BENITE, A. M. C. Aula de Química e surdez: sobre interações pedagógicas mediadas pela visão. Química Nova na Escola, São Paulo, v. 33, n. 1, p. 47-56, 2011.

PEREIRA, L. L. S.; BENITE, A. M. C. Redes sociais como espaço de interações discursivas sobre formação de professores de ciências para a educação inclusiva. Investigações em Ensino de Ciências, Porto Alegre, v.17, n. 3, p. 615-639, 2012.

PORTAL BRASIL. Apesar de avanços, surdos ainda enfrentam barreiras de acessibilidade. Governo do Brasil, 2016. Disponível em: <http://www.brasil.gov.br/cidadania-ejustica/2016/09/apesar-de-avancos-surdos-ainda-enfrentam-barreiras-de-acessibilidade>. Acesso em: 23 jan. 2018.

QUADROS, R. M. Situando as diferenças implicadas na educação de surdos: inclusão/exclusão. Universidade Federal de Santa Catarina. Revista Ponto de Vista, Florianópolis, n. 5, 2003.

RETONDO, C. G.; SILVA, G. M. Ressignificando a formação de professores de Química para a Educação Especial e Inclusiva: uma história de parcerias. Química Nova na Escola, São Paulo, n. 30, p. 27-33, 2008.

SALDANHA, J. C. O ensino de Química em Língua Brasileira de Sinais. Dissertação (Mestrado em Ensino das Ciências na Educação Básica) - Universidade do Grande Rio "Prof. José de Souza Herdy", Duque de Caxias, 2011, 160 p. 
SANTOS, E. S. Comunidade surda: a questão das suas identidades. In: DÍAZ et al. Educação inclusiva, deficiência e contexto social: questões contemporâneas. Salvador: Editora da Universidade Federal da Bahia, p. 15-25, 2009.

SOUZA, R. M; GÓES, M. C. R. O ensino para surdos na escola inclusiva: considerações sobre o excludente contexto da inclusão: In: SKLIAR, C. (Org.). Atualidade da educação bilíngue para surdos. Porto alegre: Mediação, 1999.

SOUSA, S. F.; SILVEIRA, H. E. Terminologias Químicas em Libras: A Utilização de Sinais na Aprendizagem de Alunos Surdos. Química Nova na Escola, São Paulo, v. 33, n.1, p. 3746, 2011.

VILELA-RIBEIRO, E. B.; BENITE, A. M. C. A Educação Inclusiva na percepção dos professores de Química. Ciência \& Educação, Bauru, v. 16, n. 3, p. 585-594, 2010.

ZAYED, G. H.; MEDEIROS, M. M.; RECENA, M. C. P. Cartilha sobre conceitos básicos de Química para inclusão de alunos surdos em sala de aula. Areté - Revista Amazônica de

Ensino de Ciências, Manaus, v.9, n.19, p. 123-131, 2016.

\section{SOBRE OS AUTORES}

CAROLINE TEIXEIRA GUEDES. Licenciada e Bacharel em Química pela Universidade Federal Fluminense (UFF), Niterói, Rio de Janeiro (2017/2019). Mestranda do Programa de Pós-Graduação em Química da Universidade Federal Fluminense (PPGQ-UFF) no Laboratório de Fotoquímica Molecular, na área de Química Inorgânica e Fotoquímica Molecular. Neste trabalho planejou e organizou a pesquisa bibliográfica, realizando a busca, análise dos dados, discussão dos resultados e a redação do texto.

ELUZIR PEDRAZZI CHACON. Professora Titular da Universidade Federal Fluminense. Formada em Licenciatura em Química (1985), Bacharelado em Química (1985) e Química Industrial (1987), com Doutorado em Química Orgânica (2007) pela Universidade Federal Fluminense. Atua na área de Ensino de Química, Formação Continuada de Professores e Divulgação Científica, elaborando, aplicando e avaliando metodologias e recursos educacionais. Nesse trabalho realizou a discussão dos resultados e a redação do texto. 